\title{
Hyperbaric oxygen therapy after acute ischemic stroke with large penumbra: a case report
}

\author{
Omar Hussein ${ }^{1}$, Khalid Sawalha ${ }^{2^{*}} \mathbb{D}$, Ahmed Abd Elazim', Diana Greene-Chandos ${ }^{1}$ and Michel T. Torbey ${ }^{1}$
}

\begin{abstract}
Background: Hyperbaric oxygen therapy (HBOT) for the treatment of acute stroke has been under the radar for a long time. Previous studies have not been able to prove efficacy. Several factors might have contributed to such inconsistent results. The timing of delivering the hyperbaric oxygen in relation to the stage of stroke evolution may be an important factor. This was not taken into account in the previous studies as there was no feasible and standardized method to assess the penumbra in the acute phase. Now with the perfusion scan appearing as a key player in the acute stroke management, precise stroke patient selection for hyperbaric oxygen therapy deserves a second chance similar to mechanical thrombectomy.

Case presentation: A 62-year-old female patient who presented with acute large vessel stroke was not eligible for chemical or mechanical thrombectomy. There was a large penumbra on imaging. She got treated with several sessions of hyperbaric oxygen over a 2-week period immediately after stroke. The patient showed significant improvement on the follow-up perfusion imaging as well as some clinical improvement. The more impressive radiological improvement was probably due to the presence of relatively large core infarction at baseline affecting functional brain areas. The patient continued to improve clinically on her 6-month follow up visit.
\end{abstract}

Conclusion: Our case demonstrates immediate stroke-related penumbra improvement associated with HBOT. Based on that, we anticipate a potential role for HBOT in acute stroke management considering precise patient selection. Future randomized controlled trials are needed and should take that in consideration.

Keywords: Hyperbaric oxygen therapy, Acute ischemic stroke, HBOT, Penumbra, Precision medicine

\section{Background}

The ischemic penumbra is the region of the brain that surrounds the core infarcted tissue. This region is not apoptotic yet but is at risk of progressing to an expanded core infarction unless an intervention is taken. Contrarily, cerebral oligemia is the region of the brain tissue that is temporary ischemic following a stroke but is likely to recover spontaneously and thus considered benign. In a nutshell, a core infarction is an unsalvageable tissue, a penumbra is a potentially salvageable tissue but with

\footnotetext{
* Correspondence: Khalid.Sawalhamd@baystatehealth.org

${ }^{2}$ Department of Internal Medicine, University of Massachusetts Medical

School-Baystate Campus, Worcester, USA

Full list of author information is available at the end of the article
}

intervention, and finally oligemia is a spontaneously salvageable tissue [1].

There have been remarkable advances in brain imaging in the last decade specifically in the perfusion studies. In 1980, Dr. Leon Axel has set the ground for perfusion scans to be used in mapping the cerebral blood flow by his theoretical analysis at the time [2]. With multiple techniques and softwares arising (e.g., RAPID software [3, 4]) since then, differentiation between the core, penumbra, and oligemia was made possible [5]. With such advances, vascular neurologists and neuroradiologists are able to determine with high precision the region of ischemic brain that is salvageable. This has opened the way to reinvestigate the usefulness of mechanical thrombectomy again

\section{Springer Open}

(ㅇ The Author(s). 2020 Open Access This article is licensed under a Creative Commons Attribution 4.0 International License, which permits use, sharing, adaptation, distribution and reproduction in any medium or format, as long as you give appropriate credit to the original author(s) and the source, provide a link to the Creative Commons licence, and indicate if changes were made. The images or other third party material in this article are included in the article's Creative Commons licence, unless indicated otherwise in a credit line to the material. If material is not included in the article's Creative Commons licence and your intended use is not permitted by statutory regulation or exceeds the permitted use, you will need to obtain permission directly from the copyright holder. To view a copy of this licence, visit http://creativecommons.org/licenses/by/4.0/. 
after failing in prior studies (IMS III [6], SYNTHESIS EXPANSION [7], and MR RESCUE [8]). Failure of these trails was attributed to lack of precision in patient selection due inconsistency in neuroimaging as well as using the "Merci device" instead of the "stent retriever" for mechanical thrombectomy. From 2015 through 2018, some breakthrough clinical trials (MR CLEAN [9], REVA SCAT [10]), ESCAPE [11], SWIFT PRIME [12], EXTEND-1A [13], DIFFUSE 3 [14], and DAWN [15]) has reintroduced mechanical thrombectomy in the management of acute ischemic stroke within a window of up to $24 \mathrm{~h}$ from symptoms onset respectively with remarkable success. Of note, the first three trials have relied on noncontrast CT head and CT angiography while the later four have relied on the perfusion scans (RAPID software). Consequently, mechanical thrombectomy for acute stroke management has made its way in the 2015 and 2018 AHA/ASA updated guidelines [16]. A large multicenter meta-analysis done by the HERMES group [17] showed that favorable outcomes were seen in $46 \%$ of patients enrolled in the intervention arm as compared to $27 \%$ in the control arm when pooled data from the first 5 trials were analyzed. On the other hand, When Diffuse 3 and DAWN trials were co-analyzed, $47 \%$ of the intervention group versus $15 \%$ of the control group showed favorable outcomes despite of the large window gap for intervention between the two analyses. In another analysis by the HERMES group, they showed that the estimated ischemic core volume was independently associated with functional independence and functional improvement [18]. This indicates that mechanical thrombectomy relies heavily on the perfusion imaging results and thus precise patient selection is warranted.

Recent human and animal studies showed that the penumbra can extend beyond $48 \mathrm{~h}$ and are associated with worse outcomes if not treated [19-21]. In a DAWN trial subanalysis, 21 patients who were enrolled into the study actually met the perfusion imaging criteria but did not meet the time window which extended beyond $24 \mathrm{~h}$. The average time from last known well to mechanical thrombectomy was $54.5 \mathrm{~h}$ (range 24.1-155.7 h). The results of this subanalysis were similar to the main DAWN trial. It showed that the benefit from mechanical thrombectomy extends beyond the 24-h time window. It came to the conclusion that the tissue window based on the perfusion scans is a more accurate parameter than the time window [22].

Likewise, HBOT for acute cerebral ischemia has failed in the past. A recent 2014 Cochrane review [23] concluded that HBOT is not superior to conventional treatment in terms of 6-month mortality rate (prior to the mechanical thrombectomy era). Despite that few studies showed some functional and clinical improvement; on the larger scale, these results were inconsistent. Logically, like mechanical thrombectomy, achieving reperfusion and increasing oxygen tension help improving oxygenation to ischemic areas. Unlike mechanical thrombectomy, HBOT is not expected to reach the core infarction due to blocked blood supply and thus expectedly may have less chance for reperfusion injury. Nonetheless, mechanical thrombectomy achieves reperfusion whereas HBOT delay tissue demise until revascularization is achieved or a collateral circulation is maintained. Again, precision in patient selection is a key.

We present a case of acute symptomatic ICA occlusion who was not a candidate for mechanical or chemical thrombectomy. After obtaining the family consent, the patient received several sessions of HBOT (Fig. 1) over 2 weeks immediately after the stroke. Remarkable improvement on serial perfusion scans was evident.

\section{Hyperbaric chamber}
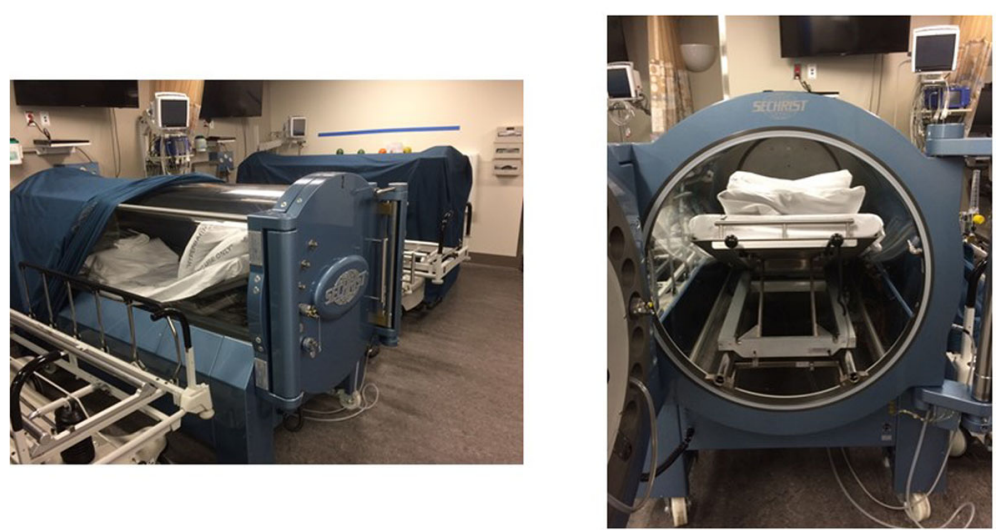

Fig. 1 Hyperbaric chamber. Image of the used hyperbaric chamber. Model 3300, company's name: Sechrist, Anaheim, California, USA, year of manufacture: 2010 


\section{Case presentation}

A 62-year-old fully functioning woman with history of hypertension and obesity presented with sudden onset right-sided weakness and global aphasia. Her last-knownwell was $>24 \mathrm{~h}$ and thus not eligible for chemical or mechanical thrombectomy. Her initial NIH stroke scale (NIHSS) was 22. CT-Head showed left-MCA hyperdense sign and watershed hypodensity in the left subcortical area. CT-Angiography showed a long segment occlusion of left internal carotid artery just cranial to bifurcation extending cranially to the level of carotid terminus. There was opacification of left-A1 segment via ACOM, trace opacification of the left ophthalmic artery and left MCA branches by left posterior communication artery, with minimal reconstitution peripherally by the leptomeningeal collaterals (Fig. 2). The initial CT-perfusion ( $\mathrm{CBF}<30 \%$ and $\mathrm{T}-\mathrm{max}>6.0 \mathrm{~s}$ ) showed an ischemic tissue size of 147 $\mathrm{ml}$ (Fig. 3). The patient received the conventional stroke therapy for secondary prevention including aspirin $81 \mathrm{mg}$ daily and a lipid lowering medication along with physical therapy and speech therapy. The patient required therapeutic hypertension due to blood pressure-dependent mental status and aphasia fluctuations indicating unstable collaterals. Therapeutic hypertension using vasopressors was maintained for 2 days post-stroke. Systolic blood pressure was maintained between 160 and $180 \mathrm{mmH} 2 \mathrm{O}$. However, the patient received five sessions of hyperbaric oxygen therapy (HBOT; hyperbaric chamber, model 3300, company's name: Sechrist, Anaheim, CA, USA, year of manufacture: 2010) over a 2-week period that started in post-stroke day 2 (after stopping therapeutic hypertension). HBOT was performed in post-stroke day 2 (PSD-2), PSD-4, PSD-7, PSD-10, and PSD-15. During that period, permissive hypertension was allowed. Systolic blood pressure was running between 100 and $140 \mathrm{mmH} 2 \mathrm{O}$. Each HBOT session consisted of $2-\mathrm{h} 100 \% \mathrm{O}_{2}$ at 2.5 ATA.
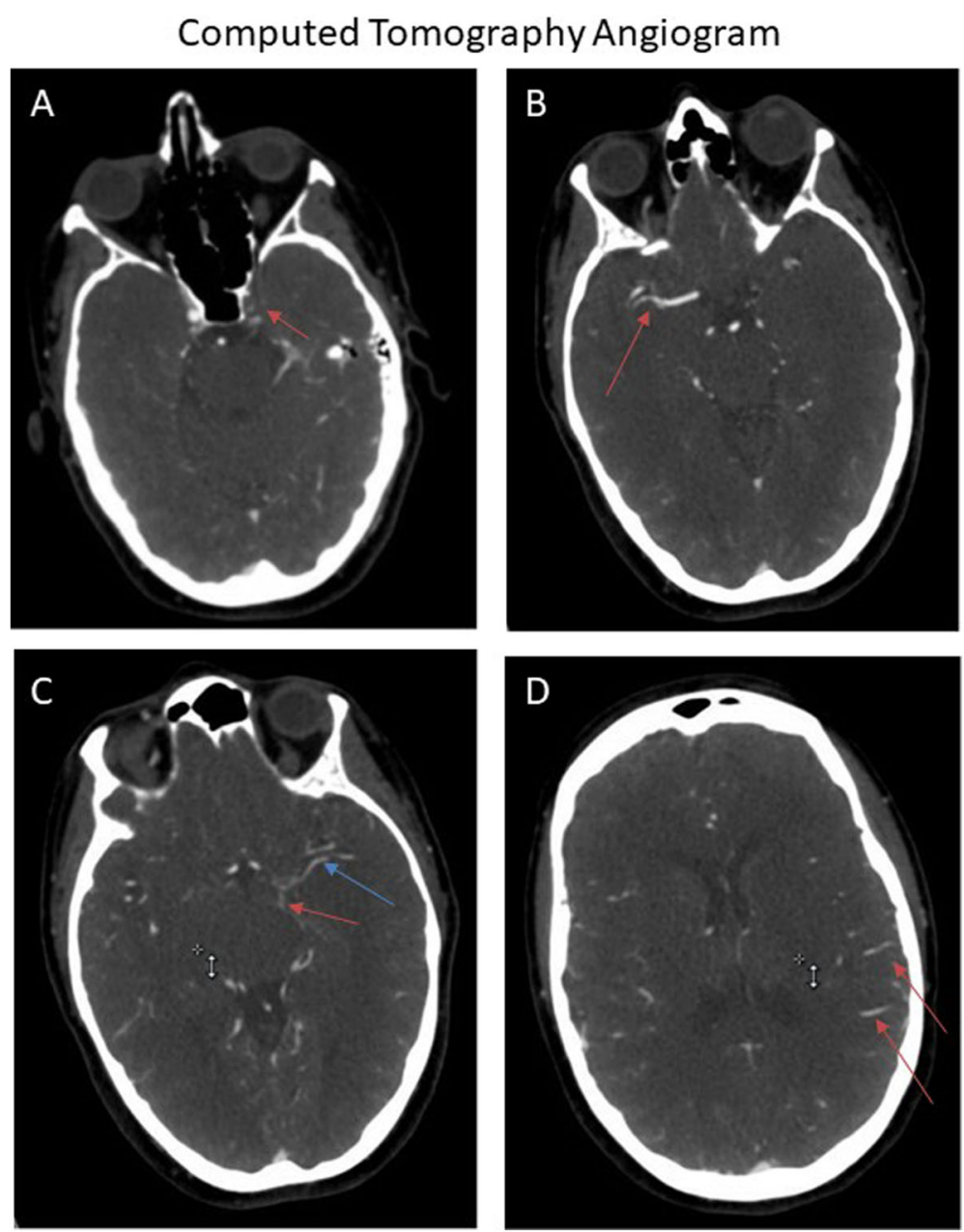

Fig. 2 Computed tomography angiogram. Presenting computed tomography-angiographic study showing complete occlusion of left intracranial portion of the internal carotid artery at the level of carotid terminus (red arrow) (a). Compared to the patent right middle cerebral artery (MCA) (b), there was trace opacification of left MCA branches (blue arrow) by left posterior communication artery (red arrow) (c), with minimal reconstitution peripherally by the leptomeningeal (red arrows) (d) 


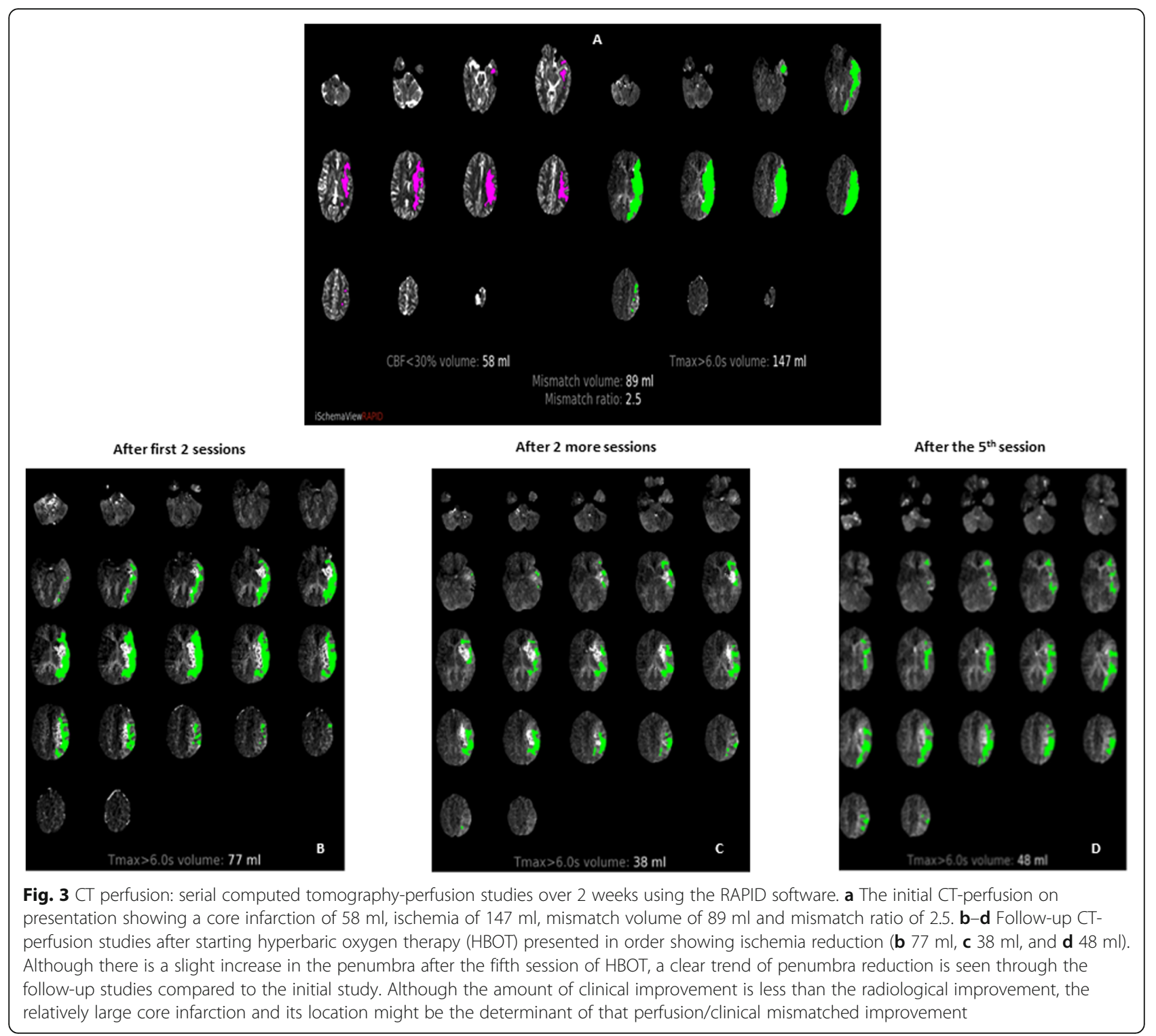

Serial CT-perfusion studies were done after the HBOT sessions (Fig. 3). The first follow-up CT-perfusion done after 2 sessions of HBOT showed reduction of the ischemic area to $77 \mathrm{ml}$. Her NIHSS improved to 16 . The second follow-up CT-perfusion after 2 more sessions of HBOT showed further reduction of the ischemic area to $38 \mathrm{ml}$. Her NIHSS improved to 12. The final CT-perfusion done after fifth session of HBOT showed near stabilization of the ischemic area at $48 \mathrm{ml}$. Her NIHSS improved to 10 . Her global aphasia improved (only motor aphasia partially persisted), and there was no clinical deterioration despite normalization of the blood pressure after 2 days due to evidence of small intracerebral hemorrhage. Her 6-month follow-up visit showed improvement of her aphasia and motor functions. Her modified ranking scale was four as she still needs assistance with walking.

\section{Discussion}

The patient showed significant improvement on the follow-up perfusion imaging as well as some clinical improvement. The lack of full-clinical improvement was probably due to the presence of relatively large core infarction at baseline affecting functional brain areas.

The proposed beneficial mechanism of HBOT includes counteracting hypoxia by inducing hyperoxemia which leads to improved perfusion and oxygenation of the penumbra and the brain microcirculation [24]. While this action seems exciting, it is not specific for hyperbaric oxygen and reports of normobaric oxygen therapy (NBOT) delivery in the acute stroke presumptively lead to the same effect [25]. While NBO is feasible, quick, and easy to use, it lacks an equivalent neuroprotective effect as HBOT. In an animal study that compared 
HBOT, NBOT, and normobaric air, the HBOT only had significantly smaller infarct size with no difference in the brain oxygenation indicating the presence of neuroprotective effect in the HBOT group [26]. The neuroprotective effect of HBOT comes from the antioxidant [27] and anti-inflammatory effects associated with it. The antioxidant effect is paradoxical and controversial as it has been also reported to induce an oxidative stress injury in the brain. However, this might be related to whether revascularization prior to HBOT was achieved or not. In other words, prior revascularization might increase the risk of oxidative injury. However, preserving HBOT for strokes that are not eligible to revascularization might sound reasonable. The anti-inflammatory effect is maintained through inhibition of leucocyte activation, regulate abnormal cellular metabolites, recovering the blood-brain barrier and thus reducing the cerebral edema [24, 28-32]. Other factors leading to neuroprotection with HBOT have been described. These include mitochondrial regulation [33], decreased cortical and hippocampal caspase-3 [34], increased growth factors [35], and reduction in hypoxia-inducible factor-1 [36]. A major risk of HBOT, as mentioned before, is the worsened oxidative stress with HBOT leading to glutamate inducted excitotoxic cell death [37]. Similar effect was reported with NBOT [38]. Another potential risk of HBOT is that it might theoretically lead to a steal phenomenon which can be detrimental. This means routing of the blood from the ischemic tissue to the normal brain tissue due to vasodilatation of the vessels on the normal side. This occurs when there is a persistent arterial occlusion that lead to hypercarbia in the ischemic region that leads to decreased flow velocities in that region at the expected time of normal brain vasodilatation induced by HBOT [39] leading to blood shift to the normal non ischemic areas. This usually leads to worsening of the patient's manifestations after an initial improvement [40]. While there has not been reports associating the steal phenomenon with HBOT, it remains a potential risk of the treatment.

The timing of HBOT for acute stroke treatment is another controversial topic. While in the past, it was believed that the earlier the treatment was started, the better the outcomes will be [41]. More recently, it is believed that later onset, whether acutely $2-5$ days poststroke or chronically, and longer course HBOT has significant effect on neurogeneration [42-44].

As previously mentioned, the previous 2014 Cochrane review was conducted before the recent breakthrough trials for validation of mechanical thrombectomy guided by the perfusion scans (precise selection of patients). Despite that the authors found no good evidence to show that HBOT improves clinical outcomes when applied during acute presentation of ischemic stroke, this was attributed to insufficient evidence by 11 RCTs.
The possibility of clinical benefit was not excluded. Similar reviews discussing failure of mechanical thrombectomy as a treatment for stroke exist before those breakthrough trials. However, they kept the door opened for further modifications [45, 46]. Nonetheless, reemergence of mechanical thrombectomy after the establishment of reliable brain perfusion scanning pursued $[47,48]$.

In the new era of precision medicine [49] and perfusion-guided therapy for acute ischemic stroke, HBOT as an alternative therapy for acute ischemic stroke, for which the traditional reperfusion methods are difficult to achieve, should be readdressed. This is especially true if a significant penumbra exists. Conditions, like symptomatic critical carotid stenosis and critical vertebral and/or basilar arteries stenosis or occlusion, are also eligible especially if the surgical option is contraindicated, unachievable, or will be delayed. While an alternative therapy like therapeutic hypertension is always an option, it might have significant side effects like bleeding and/or organ damage like myocardial infarction.

Based on that, we anticipate a larger potential role for HBOT in acute stroke management in the future considering precise patient selection. Follow-up randomized controlled trials (RCT) should take that in consideration.

\section{Limitation}

The intention of this report, like any other case report, is never to create an attribution, association, or correlation but to report an observation and draw attention for the need for such RCT. Case reports are important tools to report observations. Most major discoveries or trials were based on observations from case reports or case series. We obtained a CT perfusion scan immediately after each hyperbaric therapy which showed consistent improvement. This is the observation that we are reporting. This might be the result of natural resolution and thus we recommend that a randomized control trial should be conducted. Without the report of observations, we will never be able to conduct such trials. Nonetheless, the persistence of penumbra beyond $48 \mathrm{~h}$ is not so common. While this might be unexpected by some, it strengthen our argument that HBOT might be useful in the prevention of demise of the penumbra.

Mechanical thrombectomy itself as a treatment for stroke showed initial failure (IMS III, SYNTHESIS EXPANSION, and MR RESCUE). Without persistent clinicians reporting association of benefit after precise selection of patients based on the relatively newly developed CT perfusion imaging, they would have never been able to re-conduct trials like (MR CLEAN, REVASCAT, ESCAPE, SWIFT PRIME, EXTEND-1A, DIFFUSE 3, and DAWN) that have proven the correlation. 
Another limitation is the presence of a confounding factor for HBOT which is the induced therapeutic hypertension. This only lasted for 2 days. While this could certainly contribute to the initial improvement, the continued improvement over the pursuing 2 weeks while on HBOT might indicate a potential role for such intervention.

\section{Conclusion}

HBOT, as a salvage therapy for the cerebral ischemic penumbra, is potentially beneficial and deserves a second chance of evaluation after precise selection of patients with large vessel occlusion (LVO) strokes. Although it carries potential risks like oxidative injury, this is theoretically less significant than those associated with mechanical revascularization as the dead tissue is not subject to such stress. HBOT, if proven effective, can be an alternative, adjunctive, or back-up therapy for the treatment of patients suffering of acute LVO stroke associated with large penumbra and with anticipated delayed or contraindicated mechanical thrombectomy. Randomized controlled trials are needed to prove such hypothesis.

\section{Abbreviations}

HBOT: Hyperbaric oxygen therapy; NIHSS: National institution of health stroke scale; NBOT: Normobaric oxygen therapy

\section{Acknowledgements}

Not applicable

\section{Machine used}

Hyperbaric chamber, model 3300, company's name: Sechrist, Anaheim, CA, USA, year of manufacture: 2010

MRI: Siemens Skyra 3 Tesla, Siemens Healthineers AG, Germany, 2014

CT scan: Siemens Force, Siemens Healthineers AG, Germany, 2014

\section{Authors' contributions}

All authors contributed significantly to the manuscript writing and design. "All authors have read and approved the manuscript". OH: writing manuscript and design the case report. KS: writing manuscript and design the case report. AA: literature review. DG: literature review, reviewing manuscript. MT: reviewing and approving the manuscript. Criticizing the content and structure of manuscript.

\section{Funding}

All authors have no funding disclosure.

\section{Availability of data and materials}

Data is limited to one patient in this case report. Data is available whenever requested

\section{Ethics approval and consent to participate}

Case report $s$ are exempted from institutional board review and ethical approval.

\section{Consent for publication}

A written informed consent was obtained from the participant

\section{Competing interests}

The authors declare that they have no competing interests

\section{Author details}

'Department of Neurology, The New Mexico University Health Sciences Center, Albuquerque, USA. ${ }^{2}$ Department of Internal Medicine, University of Massachusetts Medical School-Baystate Campus, Worcester, USA.

Received: 11 May 2020 Accepted: 31 August 2020

Published online: 10 September 2020

\section{References}

1. Wu L, Wu W, Tali ET, Yuh WT. Oligemia, penumbra, infarction: understanding hypoperfusion with neuroimaging. Neuroimaging Clin N Am. 2018;28(4):599-609.

2. Axel L. Cerebral blood flow determination by rapid-sequence computed tomography: theoretical analysis. Radiology. 1980 Dec;137(3):679-86.

3. Campbell BC, Yassi N, Ma H, Sharma G, Salinas S, Churilov L, et al. Imaging selection in ischemic stroke: feasibility of automated CT-perfusion analysis. Int J Stroke. 2015;10(1):51-4.

4. Lansberg MG, Christensen S, Kemp S, Mlynash M, Mishra N, Federau C, et al. Computed tomographic perfusion to predict response to recanalization in ischemic stroke. Ann Neurol. 2017:81:849-56.

5. Kamalian S, Kamalian S, Konstas AA, Maas MB, Payabvash S, Pomerantz SR, et al. $C T$ perfusion mean transit time maps optimally distinguish benign oligemia from true "at-risk" ischemic penumbra, but thresholds vary by postprocessing technique. Am J Neuroradiol. 2012;33(3):545-9.

6. Broderick JP, Palesch YY, Demchuk AM, Yeatts SD, Khatri P, Hill MD, et al. Endovascular therapy after intravenous t-PA versus t-PA alone for stroke. N Engl J Med. 2013;368(10):893-903.

7. Ciccone A, Valvassori L, Nichelatti M, Sgoifo A, Ponzio M, Sterzi R, et al. Endovascular treatment for acute ischemic stroke. N Engl J Med. 2013;368: 904-13.

8. Kidwell CS, Jahan R, Gornbein J, Alger JR, Nenov V, Ajani Z, et al. A trial of imaging selection and endovascular treatment for ischemic stroke. N Engl J Med. 2013:368(10):914-23.

9. Berkhemer OA, Fransen PS, Beumer D, van den Berg LA, Lingsma HF, Yoo $A J$, et al. A randomized trial of intraarterial treatment for acute ischemic stroke. New Engl J Med. 2015;372:11-20.

10. Jovin TG, Chamorro A, Cobo E, de Miquel MA, Molina CA, Rovira A, et al. Thrombectomy within 8 hours after symptom onset in ischemic stroke. $\mathrm{N}$ Engl J Med. 2015;372(24):2296-306.

11. Goyal M, Demchuk AM, Menon BK, Eesa M, Rempel JL, Thornton J, et al. Randomized assessment of rapid endovascular treatment of ischemic stroke. N Engl J Med. 2015;372(11):1019-30.

12. Saver JL, Goyal M, Bonafe A, Diener HC, Levy El, Pereira VM, et al. Stentretriever thrombectomy after intravenous t-PA vs. t-PA alone in stroke. N Engl J Med. 2015;372(24):2285-95.

13. Campbell BC, Mitchell PJ, Kleinig TJ, Dewey HM, Churilov L, Yassi N, et al. Endovascular therapy for ischemic stroke with perfusion-imaging selection. N Engl J Med. 2015;372(11):1009-18.

14. Albers GW, Marks MP, Kemp S, Christensen S, Tsai JP, Ortega-Gutierrez S, et al. Thrombectomy for stroke at 6 to 16 hours with selection by perfusion imaging. N Engl J Med. 2018;378(8):708-18.

15. Nogueira RG, Jadhav AP, Haussen DC, et al. Thrombectomy 6 to 24 hours after stroke with a mismatch between deficit and infarct. N Engl J Med. 2018;378(1):11-21.

16. Powers WJ, Rabinstein AA, Ackerson T, Adeoye OM, Bambakidis NC, Becker K, Biller J, Brown M, Demaerschalk BM, Hoh B, Jauch EC. 2018 Guidelines for the early management of patients with acute ischemic stroke: a guideline for healthcare professionals from the American Heart Association/American Stroke Association. Stroke. 2018 Mar;49(3):e46-e99.

17. Goyal M, Menon BK, van Zwam WH, Dippel DW, Mitchell PJ, Demchuk AM, et al. Endovascular thrombectomy after large-vessel ischaemic stroke: a meta-analysis of individual patient data from five randomised trials. Lancet. 2016;387(10029):1723-31.

18. Campbell BCV, Majoie CBLM, Albers GW, Menon BK, Yassi N, Sharma G, et al Penumbral imaging and functional outcome in patients with anterior circulation ischaemic stroke treated with endovascular thrombectomy versus medical therapy: a meta-analysis of individual patient-level data. Lancet Neurol. 2019;18(1):46-55.

19. Christensen S, Mlynash M, Kemp S, et al. Persistent target mismatch profile $>24$ hours after stroke onset in DEFUSE 3. Stroke. 2019;50(3):754-7. 
20. Zheng W, Matei N, Pang J, et al. Delayed recanalization at 3 days after permanent MCAO attenuates neuronal apoptosis through FGF21/FGFR1/ PI3K/Caspase-3 pathway in rats. Exp Neurol. 2019;320:113007.

21. McBride DW, Wu G, Nowrangi D, et al. Delayed recanalization promotes functional recovery in rats following permanent middle cerebral artery occlusion. Transl Stroke Res. 2018;9(2):185-98.

22. Desai SM, Haussen DC, Aghaebrahim A, et al. Thrombectomy 24 hours after stroke: beyond DAWN. J Neurointerv Surg. 2018;10(11):1039-42.

23. Bennett MH, Weibel S, Wasiak J, Schnabel A, French C, Kranke P. Hyperbaric oxygen therapy for acute ischaemic stroke. Cochrane Database Syst Rev. 2014;11:CD004954.

24. Bennett MH, Weibel S, Wasiak J, Schnabel A, French C, Kranke P. Hyperbaric oxygen therapy for acute ischemic stroke. Stroke. 2015 May;46(5):e109-10.

25. Shi S, Qi Z, Lou Y, Liu KJ. Normobaric oxygen treatment in acute ischemic stroke: a clinical perspective. Med Gas Res. 6(3):147-53.

26. Hou $\mathrm{H}$, Grinberg $\mathrm{O}$, Williams $\mathrm{B}$, et al. The effect of oxygen therapy on brain damage and cerebral $\mathrm{pO}(2)$ in transient focal cerebral ischemia in the rat. Physiol Meas. 2007;28(8):963-76

27. Li J, Liu W, Ding S, Xu W, Guan Y, Zhang JH, Sun X. Hyperbaric oxygen preconditioning induces tolerance against brain ischemia-reperfusion injury by upregulation of antioxidant enzymes in rats. Brain Res. 2008 May 19; 1210:223-9.

28. Mink RB, Dutka AJ. Hyperbaric oxygen after global cerebral ischemia in rabbits reduces brain vascular permeability and blood flow. Stroke. 1995 Dec;26(12):2307-12.

29. Thom SR. Functional inhibition of leukocyte B2 integrins by hyperbaric oxygen in carbon monoxide-mediated brain injury in rats. Toxicol Appl Pharmacol. 1993;123(2):248-56.

30. Selman WR, Lust WD, Pundik S, Zhou Y, Ratcheson RA. Compromised metabolic recovery following spontaneous spreading depression in the penumbra. Brain Res. 2004;999(2):167-74.

31. Sukoff MH, Ragatz RE. Hyperbaric oxygenation for the treatment of acute cerebral edema. Neurosurgery. 1982;10(1):29-38.

32. Badr AE, Yin W, Mychaskiw G, Zhang JH. Effect of hyperbaric oxygen on striatal metabolites: a microdialysis study in awake freely moving rats after MCA occlusion. Brain Res. 2001;916(1-2):85-90.

33. Lou M, Chen $Y$, Ding M, Eschenfelder CC, Deuschl G. Involvement of the mitochondrial ATP-sensitive potassium channel in the neuroprotective effect of hyperbaric oxygenation after cerebral ischemia. Brain Res Bull. 2006;69(2):109-16.

34. Calvert JW, Zhou C, Nanda A, Zhang JH. Effect of hyperbaric oxygen on apoptosis in neonatal hypoxia-ischemia rat model [published correction appears in J Appl Physiol. 2004 Jan;96(1):405]. J Appl Physiol. 1985. 2003; 95(5):2072-80.

35. Zhang $X G$, Jiang ZL, Wang GH, et al. Zhongguo Ying Yong Sheng Li Xue Za Zhi. 2012;28(1):42-6.

36. Sun L, Marti HH, Veltkamp R. Hyperbaric oxygen reduces tissue hypoxia and hypoxia-inducible factor-1 alpha expression in focal cerebral ischemia. Stroke. 2008;39(3):1000-6

37. Yusa TO, Beckman JS, Crapo JD, Freeman BA. Hyperoxia increases H2O2 production by brain in vivo. J Appl Physiol. 1987 Jul 1;63(1):353-8.

38. Haelewyn B, Chazalviel L, Nicole O, Lecocq M, Risso Jل Abraini JH. Moderately delayed post-insult treatment with normobaric hyperoxia reduces excitotoxin-induced neuronal degeneration but increases ischemiainduced brain damage. Med Gas Res. 2011;1:2.

39. Unfirer S, Kibel A, Drenjancevic-Peric I. The effect of hyperbaric oxygen therapy on blood vessel function in diabetes mellitus. Med Hypotheses. 2008;71(5):776-80. https://doi.org/10.1016/j.mehy.2008.06.016.

40. Alexandrov AV, Sharma VK, Lao AY, Tsivgoulis G, Malkoff MD, Alexandrov AW. Reversed Robin Hood syndrome in acute ischemic stroke patients. Stroke. 2007:38(11):3045-8

41. McCormick JG, Houle TT, Saltzman HA, Whaley RC, Roy RC. Treatment of acute stroke with hyperbaric oxygen: time window for efficacy. Undersea Hyperb Med. 2011;38(5):321-34

42. Lee YS, Chio CC, Chang CP, et al. Long course hyperbaric oxygen stimulates neurogenesis and attenuates inflammation after ischemic stroke. Mediat Inflamm. 2013:2013:512978

43. Chen $\mathrm{CH}$, Chen SY, Wang V, et al. Effects of repetitive hyperbaric oxygen treatment in patients with acute cerebral infarction: a pilot study. Sci World J. 2012;2012:694703
44. Efrati S, Fishlev G, Bechor Y, et al. Hyperbaric oxygen induces late neuroplasticity in post stroke patients--randomized, prospective trial. PLoS One. 2013;8(1):e53716.

45. Yamagami $\mathrm{H}$, Sakai N. Current status of endovascular therapy for acute ischemic stroke. Rinsho Shinkeigaku. 2013;53(11):1166-8.

46. Mokin M, Khalessi AA, Mocco J, et al. Endovascular treatment of acute ischemic stroke: the end or just the beginning? Neurosurg Focus. 2014; 36(1):E5.

47. Campbell BC, Mitchell PJ, Kleinig TJ, et al. Endovascular therapy for ischemic stroke with perfusion-imaging selection. N Engl J Med. 2015;372(11):1009-18.

48. Fisher M, Albers GW. Advanced imaging to extend the therapeutic time window of acute ischemic stroke. Ann Neurol. 2013;73(1):4-9. https://doi. org/10.1002/ana.23744.

49. Hinman JD, Rost NS, Leung TW, Montaner J, Muir KW, Brown S, et al. Principles of precision medicine in stroke. J Neurol Neurosurg Psychiatry. 2017;88(1):54-61.

\section{Publisher's Note}

Springer Nature remains neutral with regard to jurisdictional claims in published maps and institutional affiliations.

\section{Submit your manuscript to a SpringerOpen ${ }^{\circ}$ journal and benefit from:}

- Convenient online submission

- Rigorous peer review

- Open access: articles freely available online

- High visibility within the field

- Retaining the copyright to your article

Submit your next manuscript at $>$ springeropen.com 